\title{
"EL PODER ESTÁ EN EL MAR" LA EXPEDICIÓN DE LOS HERMANOS NODAL (1618-1619)
}

\author{
DAVID RodRíGuez Couto \\ Universidad Nacional de Educación a Distancia
}

\begin{abstract}
Resumen. La expedición de los hermanos Nodal al estrecho de Magallanes y Tierra de Fuego (1618-1619) se llevó a cabo en vísperas de la finalización de la Tregua de los Doce Años (1609-1621), entre la República de Holanda y la Monarquía Hispánica, para verificar el nuevo paso interoceánico descubierto por la expedición holandesa comandada por Jacob Le Maire y Willem Schouten en 1616. Este artículo pretende realizar un nuevo análisis de esta expedición para aproximarnos al significado que tuvo en el contexto político de aquel tiempo que gira en torno a una idea: el dominio de los mares. Esta idea se manifestó durante el reinado de Felipe III tanto en el plano material como en el plano ideológico y tuvo sus influjos en la organización de esta expedición marítima. Los logros náuticos y cartográficos de la misma, demuestran la capacidad material y el potencial humano de la Monarquía Hispánica a inicios del siglo XVII. Su éxito también se debió a una cooperación ibérica, posible en aquel tiempo en el que las coronas de España y Portugal estaban unidas en un mismo destino.
\end{abstract}

Palabras clave: hermanos Nodal, expediciones marítimas, cartografía, Felipe III, siglo XVII.

Abstract. The Nodal brothers' expedition to the Straight of Magellan and Tierra de Fuego was undertaken shortly before the completion of the Twelve Years' Truce between the Spanish Monarchy and the Dutch Republic (1609-1621), to verify the new interoceanic pass discovered by the Dutch expedition commanded by Jacob Le Maire and Willem Schouten in 1616. This article tries to realice a new analysis of this expedition to approximate the meaning it had in the political context of that time around an idea: the domain of the seas. This idea manifested itself during Philip III's reign both on the material and ideological context and had its influence on the organization of this maritime expedition. It's nautical and cartographic achievements,

Recibido: 9-4-2018 · Aceptado: 28-6-2018·davidrcouto@gmail.com 
demonstrate the material capacity and the human potential of the Hispanic Monarchy at the beginning of the $17^{\text {th }}$ century. Its success was also due to an Iberian cooperation, possible at that time when the Spanish and Portuguese crowns were united in same destination.

Keywords: Nodal brothers', naval expeditions, cartography, Philip III, $17^{\text {th }}$ century.

«... Floreció ansimismo en disciplina militar de valerosos y ejercitados capitanes y tan heróicos y esforzados en las empresas como expertos y avisados en el consejo, $[\ldots]$ adelantando sus términos en la América; sus armadas fueron el terror y espanto de las naciones, ora doblando el cabo de Buena-Esperanza, ora penetrando el angosto estrecho de Magallanes ó el agora más extendidamente descubierto, domando varias gentes y calando nuevos y nunca vistos mares» ${ }^{1}$.

ESTAS LÍNEAS, escritas como proemio a la historia de Felipe III por el cronista y cortesano Matías de Novoa (1576-1652), revelan la impronta de la exitosa empresa naval llevada a cabo en aquel reinado: la expedición encomendada en 1618 a los pontevedreses hermanos Nodal, conocida en los documentos de aquel tiempo como «la jornada al estrecho».

Bartolomé García de Nodal y su hermano, Gonzalo de Nodal, eran experimentados capitanes y curtidos marinos que contaron con brillantes carreras militares. Ambos habían nacido en Pontevedra, una villa de vocación marinera, que por aquel entonces era un importante centro del cabotaje gallego y el mayor núcleo urbano del viejo reino de Galicia. La poderosa cofradía del Corpo Santo - a la cual perteneció su padre, Amaro de Montemeán, El Viejo - es un claro reflejo de la posición hegemónica que los mareantes locales alcanzaron al calor de esa realidad socioeconómica pontevedresa a la que nos hemos referido. En la villa, que a finales del siglo XVI conocía aún una fase de relativo esplendor, se cultivaban intensas relaciones comerciales y humanas, que ligaban muchas vidas al mar, tal y como les ocurrió a nuestros protagonistas (Pereira Fernández, 2000, pp. 15-16, pp. 90-95 y p. 117).

A través de su relación de servicios ${ }^{2}$, sabemos que comenzaron sus andanzas al enrolarse en 1590 en la Armada del Mar Océano, «sirviendo de aventureros sin sueldo», teniendo Bartolomé 16 años y Gonzalo $12^{3}$. Los hermanos siempre buscaron ocasión para distinguirse y pronto contaron con la admiración y amistad, entre

Colección de documentos inéditos para la historia de España (en adelante CODOIN), 1875, tomo LX, p. 10.

2 «Relación sumaria de los servicios de los capitanes Bartolomé García de Nodal y Gonçalo de Nodal, su hermano». Adjuntada a la relación publicada de su viaje (Nodal, 1621).

Nodal, 1621, Relación sumaria de los servicios... h. 2 r. 
otros, de generales como Pedro de Zubiaur o Luis Fajardo, quienes aprobaban sus servicios. De este modo, los veremos participando en escenarios dispares, reflejo de las necesidades que tenía un imperio global, caso de las campañas de Irlanda e Inglaterra, la batalla de las Salinas de Araya (1605), en las Indias, o en las operaciones militares llevadas a cabo por Felipe III en el Mediterráneo, donde Bartolomé rendiría 25 navíos enemigos en la bahía de la Goleta $(1609)^{4}$, y por cuya actuación en la Mamora en 1614 se le reconocería «uno de los singulares servicios que se han hecho a su Majestad, con beneficio de toda la Cristiandad $»^{5}$. Fue después de ella que el rey acrecentaría su sueldo de capitán, «por haber sido el primero que en la empresa de la Mamora saltó en tierra con sus armas» $\aleph^{6}$.

Bartolomé falleció en 1622 bajo las órdenes del Marqués de Cadereyta, cuando escoltando la flota de Indias a su regreso de Tierra Firme, una tormenta en el canal de las Bahamas ocasionó uno de los naufragios más trágicos de su tiempo ${ }^{7}$. Las últimas noticias que tenemos de Gonzalo son también de ese mismo año y nos informan de su designación como «cabo de la gente de mar» en la flota aprestada por el asentista Francisco de Mandojana, la cual zarpó con un contingente de infantería al mando del maestre de campo don Íñigo de Ayala y Mendoza para auxiliar a los colonos de Chile de los envites de los araucanos ${ }^{8}$. Un año antes, el mencionado Gonzalo había dirigido un memorial al rey Felipe III trasladándole su preocupación por mejorar ciertos aspectos de las fuerzas navales. Su lectura pone de relieve la experiencia del autor en distintos ámbitos, como el de la construcción naval — derivado, sin duda, de su cargo de superintendente de los galeones de Coruña-, y su buen conocimiento del mundo marítimo de la época9.

$4 \quad$ Nodal, 1621, Relación sumaria de los servicios... h. 2 v.-7 r.

Nodal, 1621, Relación sumaria de los servicios... h. $10 \mathrm{v}$.

Nodal, 1621, Relación sumaria de los servicios... h. $10 \mathrm{v}$.

Archivo General de Indias (en adelante AGI), Contratación, 348 B, N. 1, R. 26, ff. 4 r.-4 v. Carta de poder dada por Juan Núñez de Nodal, embarcado en el galeón Nuestra Señora de Atocha, al capitán Bartolomé García de Nodal para que en su nombre pueda otorgar su testamento y última voluntad, Mar Caribe, 18 de mayo de 1622; AGI, Escribanía de Cámara, 1080 A, Gastos realizados para la búsqueda de la plata de los galeones N.S. de Atocha y La Margarita que se perdieron en el paraje de Matacumbé en 1622.

8 AGI, Patronato, 229, R. 62. Se propone por la Junta de Guerra que las mercedes hechas a Iñigo de Ayala y Gonzalo de Nodal por llevar el socorro a Chile, se han de entender yendo por los estrechos de Maire y San Vicente, 21 de junio de 1622; AGI, Contratación, 1172, reg. $n^{\circ} 3$., Registros de ida a Nueva España, Tierra Firme y Chile, 1622; AGI, Contratación, 1172, N. 3, R.1., Registro del navío Nuestra Señora del Juncal, 1622.

9 Real Academia de la Historia (en adelante RAH), 2011, vol. XXII, pp. 129-130, conservado en la Biblioteca Nacional de España (en adelante, BNE), ms. 12856, ff. 137 r.-158 v. Memorial hecho por el capitán Gonzalo de Nodal para dar a Su Majestad, en nombre de todas las rías de Galicia, con muchos papeles importantes para el gobierno de escuadras y armadas, 1620. 
Sin embargo, el reconocimiento póstumo de los hermanos se produjo a consecuencia de su famoso viaje austral, recordado cuarenta años más tarde por autores como fray Felipe de la Gándara como una de las más célebres hazañas de aquellos tiempos (1987, Cap. XXXVII, p. 501). Ya en el siglo XVIII, el erudito fray Martín Sarmiento consideraba necesario reimprimir la relación de su viaje para de este modo recuperar todo el conocimiento náutico y cartográfico que contenía:

«... cuya relación de la dicha navegación es muy apreciable de los extraños y poco conocida de los españoles, siendo así que está impresa en Madrid, y en cuarto, el año de 1621. Tengo ese tomo que tiene una grande carta hidrográfica y derrotero con voces castellanas, que se debe restituir y reimprimir, según mi sistema». (Sarmiento, 2008, vol. II, p. 328)

La preocupación de Sarmiento por esta reimpresión se hallaba muy en la línea del pensamiento ilustrado de la época, interesado en dar a conocer el saber científico. Aunque será solo a partir de la segunda mitad del siglo XVIII, en coincidencia con la promoción de diversas expediciones científicas en España, que su demanda se vería cumplida, al realizarse una nueva edición de la relación del viaje de los Nodal como parte de la publicación que la Imprenta Real de Marina del departamento de Cádiz hizo sobre derroteros fundamentales de la navegación llevada a cabo en las aguas del Nuevo Mundo (1766). No en vano, aquella expedición había tenido una clara misión cartográfica y científica, ya que contó con la presencia del cosmógrafo Diego Ramírez de Arellano, un hombre de ciencia de la época, que, junto al resto de la tripulación, zarparon el 27 de septiembre de 1618 de Lisboa en las carabelas Nuestra Señora de Atocha y Nuestra Señora del Buen Suceso, iniciando así una travesía que duraría nueve meses y doce días, durante los cuales ambas navegaron cerca de cinco mil leguas.

Además de cumplir con la misión de verificar la existencia del nuevo paso interoceánico entre el Atlántico y el Pacífico hallado por la expedición holandesa de Le Maire y Schouten dos años antes, descubrieron las islas que hoy día tienen el nombre de Diego Ramírez, en honor al cosmógrafo de la expedición, y alcanzaron un nuevo récord en la navegación hacia latitudes australes ${ }^{10}$. En aquellas lejanas tierras realizaron el reconocimiento cartográfico más preciso de su época, el cual apareció luego recogido en el conocido mapa que se adjuntó de a relación del viaje. Una travesía gracias a la cual lograron circunnavegar por primera vez la Tierra de Fuego y realizar los primeros contactos de los que se tienen noticia con sus habitantes (Mapa 1).

El 16 de febrero de 1619 alcanzaron la mayor latitud de su derrota, estimada entre $58^{\circ}$ y $59^{\circ}$ Sur. Esta latitud no será superada hasta 1775 por el capitán James Cook. 


\section{Mapa 1. Derrotero de la expedición de los hermanos Nodal}

(27 de septiembre de 1618 -9 de julio de 1619)

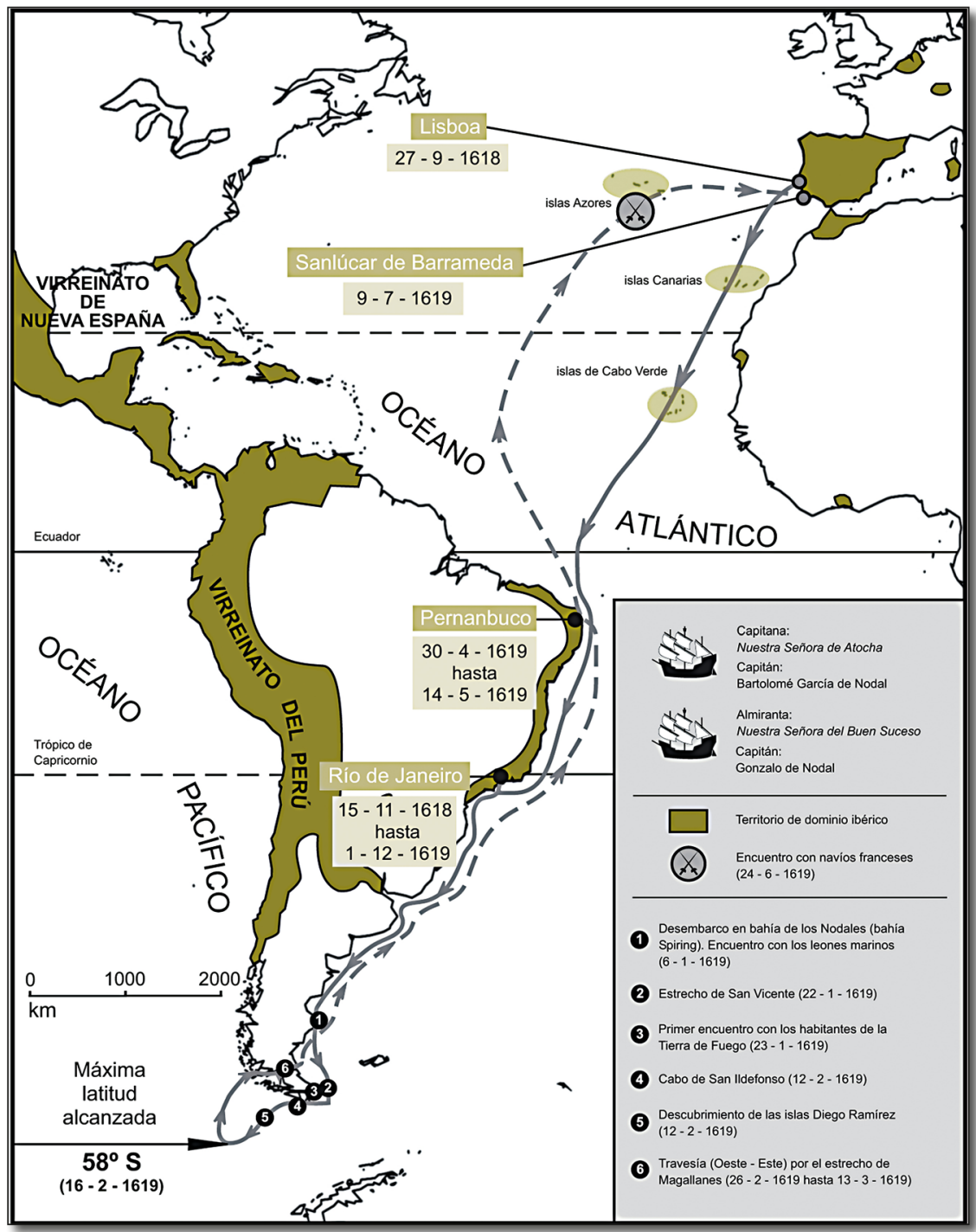

Fuente: Elaboración propia a partir de la relación del viaje. 
A pesar de que la expedición constituyó todo un éxito a los ojos de la Monarquía Hispánica, su trascendencia en la historiografía fue más bien discreta. $\mathrm{Su}$ adscripción cronológica a un siglo considerado de crisis y decadencia hispánica no ayudó a ello, como tampoco el que se produjese durante el reinado de Felipe III, enmarcado como sabemos entre los de Felipe II y Felipe IV, que suscitaron una mayor atención entre los investigadores. Junto a ello, la actividad marítima española del siglo XVII suele ensombrecerse al ser contrastada con la época dorada de las expediciones marítimas holandesas, las cuales, por el contrario, gozaron de una difusión editorial extraordinaria.

En lo que nos ocupa, las recopilaciones realizadas durante el siglo XIX en el ámbito de la Marina Española con intención de hacerse eco de las glorias navales pasadas siguen siendo obras de referencia (Fernández de Navarrete, 1842, tomo I, pp. 213-218, pp. 353-354 y pp. 595-596; Ferrer de Couto, 1849, vol. 2, p. 559; Fernández Duro, 1896, vol. III, pp. 333-378). Fuera del ámbito militar, también desde el siglo XIX distintos autores se han interesado por la expedición o por la vida de los hermanos Nodal, al punto de que, en distinto grado, han extractado o comentado distintos pormenores de la misma contenidos en la relación del viaje, destacando la particular atención que al respecto recibieron en Galicia y su ciudad natal (González de Zúñiga, 1846, pp. 124-128; Fulgosio, 1867, pp. 68-70; Vicetto, 1873, tomo VII, pp. 215-217; Vesteiro Torres, 1874, tomo III, pp. 51-58; Rodríguez Seoane, 1889, pp. 251-252; Portela Pérez, 1891; Sampedro y Folgar, 1900, pp. 148-192; Millán, 1920, tomo I, pp. 148-192; Fernández Villamil, 1952; González García-Paz, 1961, pp. 5-11; Oyarzun, 1976, pp. 185-199; Gómez Canedo, 1991, pp. 84-85; Landín Carrasco, 1991, pp. 96-112; Vázquez de Acuña, 1996; Vicente Maroto, 2001, pp. 7-28; Filgueira Valverde, 1944a, 1944b, pp. 13-14; ID, 1946, pp. 176, 248; ID, 1963, pp. 31-33; ID, 1965, ID, 1967).

Aunque en los últimos años se ha abordado el estudio del manuscrito del cosmógrafo de esta expedición en el marco de la Historia de la Ciencia (Díaz Hernández, 2010), carecemos sin embargo de un análisis histórico que suponga un claro avance con respecto a lo expuesto en su momento por la historiografía del siglo XIX. Por esta razón, la revisión planteada en este trabajo pretende ofrecer un nuevo punto de vista a partir de los resultados contenidos en los estudios que se han ocupado de las motivaciones de la expansión y exploración ultramarina, relacionando y comparando lo sucedido en este sentido con acontecimientos y procesos históricos a escala global (Elliott, 2009, 2011), como también con aquellos que han incidido en la vinculación que ha tenido el poder político con el conocimiento cartográfico (Portuondo, 2009; Brendecke, 2012), o con los que resultan del análisis del ámbito ultramarino desde la perspectiva de la Unión Ibérica (1580-1640) (Valladares, 2001; Martínez Shaw y Martínez Torres, 2014). 
Dicho esto, este trabajo, y aun siendo deudor de los estudios precedentes, tratará de ofrecer una interpretación que nos aproxime al significado que en la época tuvo la expedición de los hermanos Nodal. Para ello, será necesaria contextualizarla en el panorama político e ideológico de comienzos del siglo XVII y situarla en el marco de un escenario global donde las grandes potencias del momento luchaban entre sí por hacerse con el control del poder marítimo, y eso, sin olvidar la posición que dicha expedición ocupó en el seno de la política internacional emprendida por Felipe III y, de manera muy particular, en la política marítima y naval que dicho monarca amparó y potenció durante su reinado. Teniendo en cuenta que el éxito de la expedición no se debió al azar, incidiremos asimismo sobre la cooperación ibérica que se produjo en torno a la misma, la cual, responde a la realidad política que en aquel momento se deriva de la Unión Ibérica. Junto a ello, esta expedición marítima nos ofrecerá, finalmente, un ejemplo ilustrativo de la importancia que los contemporáneos otorgaban a la cartografía en un mundo en expansión.

\section{La cuestión del dominio de los mares}

A comienzos del siglo XVII la Monarquía Hispánica se asentaba sobre unos vastos dominios resultado de la Unión Ibérica y de sus respectivos imperios en ultramar. Estos territorios, repartidos por todo el orbe, dependían de las rutas marítimas para su supervivencia y desde un principio en ella se hizo evidente la importancia del poderío marítimo. Por su parte, la corte de Madrid pronto empezó a temer por la posible pérdida de su imperio ultramarino frente al pujante crecimiento que experimentaba el poder naval holandés.

Las causas de este temor se gestaron en las últimas décadas del siglo XVI, pues a estos «súbditos rebeldes», a los que ahora se negaba la independencia, se les intentó excluir del comercio con las Indias mediante el cierre o el bloqueo comercial de sus puertos, circunstancia que los animó a entrar directamente en contacto con los mercados americanos al verse privados de sus beneficios por sus tradicionales intermediarios peninsulares. La expansión comercial marítima holandesa se dejó sentir sobre los intereses ibéricos en Asia y América mediante una serie de acciones hostiles que se convertirían en algo cotidiano a lo largo del primer tercio del siglo XVII. En este sentido, la Tregua de los Doce Años (1609-1621), como la llamada Pax Hispanica de Felipe III, fue muy relativa, ya que nunca supuso que se hubiese alcanzado una paz total en todos los territorios del imperio español (Murteira, 2008, 2014; Stradling, 1992, p. 78; Lynch, 2010, pp. 399-400).

Por otra parte, es importante señalar que la amenaza holandesa no sólo se circunscribía al plano puramente geoestratégico, a la totalidad del imperio ibérico, 
sino que fue acompañada de una ofensiva ideológica que atacaba y cuestionaba los derechos jurisdiccionales derivados de la entrada en vigor de las Bulas Alejandrinas y el Tratado de Tordesillas. De hecho, en paralelo a la expansión marítima flamenca se produjo el desarrollo de sus fundamentos teóricos de la mano del jurista holandés Hugo Grocio (1583-1645). En 1608, la Compañía Holandesa de las Indias Orientales (Vereenigde Oostindische Compagnie, VOC) le encargó la redacción de una obra, que se publicaría el mismo año en que se firmaba la Paz de Amberes (1609). Conocida como Mare Liberum, defendía la libertad de navegación de los buques por los océanos y mares del mundo, dotando así de legalidad a las actividades marítimas que llevaban a cabo sus compatriotas ${ }^{11}$. De este modo, la obra de Grocio iniciaba una batalla ideológica, al enfrentar las ideas de libertad y dominio marítimo (mare liberum versus mare clausum); en ella, hubo numerosos contendientes, partidarios y detractores de las mismas. En el ámbito ibérico, sin duda, uno de sus mayores opositores fue el portugués fray Serafín de Freitas, en cuya obra De justo Imperio Lusitanorum Asiatico (1625), se expresa con claridad meridiana la vieja tradición portuguesa del monopolio marítimo (Grocio, 1979, pp. 14-38; Martínez Torres, 2017). Esta lucha tenía lugar sobre un escenario global, caracterizado por un contexto político que giraba en torno a una sola idea: hacerse con el dominio de los mares, algo que era capital para controlar el comercio, obtener riquezas y estar a la cabeza del mundo (Martínez Torres, 2017, pp. 80-88).

Fueron años en los que del lado español se generalizó la creencia de que la tregua de 1609-1621 había favorecido el desarrollo naval de sus rivales, perjudicado al catolicismo y cuestionado el prestigio, las proezas militares y la economía hispana (Allen, 2001, p. 330). Muestra de ello, la tenemos en el memorial anónimo que llegó a las manos de Felipe III en febrero de 1618, escrito en un tono desfavorable a la paz con ingleses y los rebeldes holandeses y partidario, en cambio, de la necesidad de aumentar el poder naval español para la mejor defensa del imperio. De ahí que aconsejase al monarca se tomasen para ello ciertas medidas y decisiones en el terreno diplomático, económico y militar (Sanz Camañes, 2008, pp. 1345-1347). Aunque, probablemente, a esas alturas del reinado de Felipe III, la decisión de entrar en guerra con los holandeses una vez expirada la tregua ya había sido tomada (Stradling, 1992, pp. 76-77).

En este contexto, se recibió en la corte la noticia del descubrimiento por los holandeses de un nuevo paso interoceánico entre el Atlántico y el Pacífico. A la preocupación que esto generó, se sumó la causada por la destrucción de Santo Tomé y

11 Mare Liberum, sive de jure quod Batavis competit ad Indicana commercia dissertatio, Lugduni Batavorum, Exofficina Ludovici Elzevirÿ, 1609. 
el ambicioso intento de Sir Walter Raleigh (1552-1618) de anular el dominio ibérico sobre la Guyana. Estos acontecimientos contribuyeron, sin duda, a agravar y a alimentar los temores existentes sobre una posible pérdida del imperio ultramarino. La respuesta a esta inquietud se produjo en 1618 y nos conduce a la persona del que fue el personaje más destacado en la política exterior de aquellos años: don Diego Sarmiento de Acuña, I conde de Gondomar (1567-1626). Buen conocedor de los signos de su tiempo, así de clarividente se mostraba en una conocida misiva dirigida al monarca, cuando afirmaba que «en el aumento de los navíos y los navegantes consiste la grandeza y conservación de España, porque el mundo está reducido hoy a que el que es señor del mar, lo sea también de la tierra» (Elliott y De la Peña, 1978, p. 142). De su capacidad para actuar conforme a estas convicciones tenemos noticias, por ejemplo, a través de las presiones que ejerció sobre el rey Jacobo I antes de concluir su embajada en Inglaterra, al objeto de que ejecutase en el patíbulo de Westminster a Sir Walter Raleigh a su regreso de la expedición de las Indias occidentales que tanto daño había hecho a los españoles (1618); una ejecución que sería una de las victorias más sonadas de toda su carrera diplomática (Pérez Bustamante, 1928, p. 22 y ss., 1983, pp. 377-386).

Menos conocida es la relación que el conde de Gondomar tuvo con los hermanos Nodal. De ella nos informaba en 1961 Sebastián González García-Paz, quien transcribía y publicaba en ese año una carta fechada en Lisboa el 27 de abril de 1607, en la que Antonio Troncoso y Ulloa recomendaba a Gonzalo de Nodal y su hermano Bartolomé a don Diego Sarmiento de Acuña. El escrito de Troncoso nos presenta a los hermanos como muy honrados gallegos y muy valientes soldados y suplica al citado don Diego les haga merced, ya que «y por lo que sé es Vmd aficionado a los que son buenos soldados y honrados gallegos, suplico a Vmd como a tan mi señor le haga merced que a todos los de aquel Reino Vmd hace» (González García-Paz, 1961, pp. 5-6).

Al poco del regreso de la expedición de los Nodal, se conocen dos cartas que escribe Gonzalo al conde de Gondomar. Una, fechada el 14 de diciembre de 1619, lamenta el regreso del conde a Inglaterra cuando él y su hermano necesitaban de su favor para unas pretensiones y aprovecha para recomendarle que haga el viaje a la isla por tierra, para a continuación, ofrecérsele a guiarlo si se decidiese finalmente a ir por mar $^{12}$. La otra misiva data del 6 de enero de 1620, y en ella Gonzalo informa a Gondomar de un proyecto de defensa de los puertos y costas de Galicia, acompañado de una relación de su actual estado, para finalizar volviendo a ofrecerle sus servicios: 
«y cuando V.S. determine ir por mar, tiene aquí V.S. dos criados que le han de ir sirviendo, que conforme a sus deseos creo procurarán acertar y dar gusto» ${ }^{13}$.

Gondomar había conocido a los hermanos Nodal once años antes de su famosa expedición y todo apunta a que sus destacadas carreras militares fueron para él una buena carta de presentación. Tal vez influyera en ello su querencia por los hombres de armas naturales del reino de Galicia; una querencia que ya había dejado clara en la conocida misiva que había dirigido al secretario de Estado Andrés de Prada en 1614 , y en la cual alababa los notorios servicios que para la mayor honra y gloria de la monarquía española habían hecho tantos y tantos gallegos ${ }^{14}$. Todo esto sugiere la más que probable implicación del máximo exponente de la diplomacia hispana de la época en la elección de los hermanos para llevar a término esta empresa marítima en el que fue el año de su apoteosis.

Sea como fuere, sabemos que las trayectorias y cualidades de los Nodal como marinos eran bien conocidas y respetadas por los expertos en la materia, caso de Diego Brochero, miembro del Consejo de Guerra, quien a su vez había recomendado sus nombres al citado consejo ${ }^{15}$. Debe tenerse en cuenta la experiencia con la que contaban ambos hermanos en la Armada del Mar Océano y, particularmente, en la escuadra de galeones portuguesa que, con base en Lisboa, constituía el núcleo de la fuerza naval que tenía como misión proteger la ruta atlántica a las Indias, patrullando desde el cabo de San Vicente a las islas Azores (Rahn Phillips, 1986, p. 34). La documentación que hemos encontrado al respecto en el Arquivo Nacional da Torre do Tombo acredita la experiencia adquirida por los Nodal en esta importante base de operaciones marítimas durante el reinado de Felipe III, en el que sabemos realizaron los preparativos de la expedición que luego dirigirían ${ }^{16}$. De igual forma, el nombramiento de Diego Ramírez de Arellano como cosmógrafo de la expedición es

BNE, ms. 18.422, f. 6 r.

BNE, ms. 2348, nº 18, ff. 105 r.-108 v. Carta de Diego Sarmiento de Acuña al secretario de Estado Andrés de Prada en defensa de los ilustres gallegos y de sus proezas, que habían sido injuriados por el padre Brito en su libro Monarquía Lusitana, Londres, 27 de enero de 1614.

15 Nodal, 1621, Dedicatoria al lector, h. 2 r.

16 Arquivo Nacional da Torre do Tombo (en adelante, ANTT), Corpo Cronológico, Parte II, maço 308, doc. 34, f. 1 r., Conocimiento de pago que hace el capitán Gonzalo de Nodal, al servicio de la Armada del Mar Océano en Lisboa, de 220 reales a cuenta de su sueldo que recibe de Jerónimo de Vitoria, pagador real de la Armada. Lisboa, 3 de agosto de 1605; ANTT, Corpo Cronológico, Parte II, maço 334, doc. 32, Conocimiento de pago de dos libranzas de 10 escudos al capitán Bartolomé García de Nodal. Primera, por reformar y embargar diferentes navíos en Setúbal para el servicio de la Armada. Segunda, por embargar dos carabelas en Setúbal para que sirvan en la Armada. Lisboa, 4 de agosto de 1617; ANTT, Corpo Cronológico, Parte II, maço 334, doc. 82, f. 1 r., Conocimiento de pago que recibió el alguacil real de la armada, Pedro Martínez de Linar, del capitán Bartolomé García de Nodal encargado del aprovisionamiento de la aguada para la Armada del Mar Océano que se llevó a cabo en la localidad de Lagos, Lisboa, 6 de octubre de 1617. 
fruto de la intención de poner al servicio de la empresa el mejor potencial humano que se posee, eligiendo para ella a un individuo que era capaz de dominar todo el instrumental náutico y astronómico que existía en el momento, al objeto de reconocer con la mayor exactitud posible aquellas lejanas tierras ${ }^{17}$ (Díaz Hernández, 2010, pp. 42-46; Vicente Maroto, 2001, p. 12). El nuevo cariz que tomaba la política exterior de Felipe III no podía contemplar ni admitir ningún fracaso en la respuesta que había que dar al desafío holandés. En este sentido, cabe pensar que en 1618, cuando se produce el ajusticiamiento de Sir Walter Raleigh y se arma la exitosa expedición de los hermanos Nodal, el monarca buscaba asestar un golpe, cierto que simbólico, a las potencias rivales que competían y luchaban con España por el poderío marítimo; un golpe en el campo de la autoridad y en el de la reputación marítima de los descubrimientos geográficos.

\section{Revitalización naval y cooperación ibérica}

Durante el reinado de Felipe III se puso en marcha un acelerado proceso de rearme y construcción naval (Valdez-Bubnov, 2011, p. 74). Con él, y entre otras cosas, se pretendía dar solución a ciertos problemas, como la carencia de pilotos, la necesidad de mejorar la cartografía o la mejora y perfeccionamiento del arte de navegar. Acerca de esto último, el reto del momento era determinar la longitud en alta mar. Con la intención de abordarlo, Felipe III llegó a convocar un concurso que premiaría a quien resolviese la cuestión, lo que atrajo la atención de hombres de ciencia de todos los países. Por ejemplo, Galileo Galilei se presentó al mencionado concurso en 1619 ofreciendo a las autoridades españolas, además de sus cálculos, un invento para ver los bajeles enemigos diez veces más lejos que lo que podía hacerse a simple vista (Cotarelo Valledor, 1935, pp. 70-73; López Piñero, 1979, p. 379). Al lado de estos problemas técnicos, otra cuestión relevante para las armadas de la época era el suministro regular de tripulaciones, tema este ampliamente estudiado por José Manuel Vázquez Lijó, y que el monarca intentó solventar promulgando las Ordenanzas para reclutamiento de personal para las armadas el 4 de noviembre de 1606. Muestra de la continuidad inmediata de esta política fue el establecimiento de la Matrícula de Mar a comienzos del reinado de Felipe IV. Sin embargo, este sistema

$17 \quad$ Véase al respecto el manuscrito que redactó tras el viaje (1621): Reconosimiento de los estrechos de Magallanes y San Vicente, con algunas cosas curiosas de navegación por el capitán Diego Ramírez de Arellano, cosmógrafo y piloto mayor del Rey en la Contratación de Sevilla, BNE, ms. 3190, Contiene el mapa que elaboró Diego Ramírez de Arellano tras el viaje (dimensiones: 410 x $365 \mathrm{~mm})$. 
de inscripción ideado en el programa de rearme naval de Olivares fracasó y no volvió establecerse hasta el siglo XVIII (Vázquez Lijó, 2007, pp. 57-83 y p. 465).

Sin embargo, esta voluntad de revitalización naval encontró no pocas dificultades para materializarse. Como en su día mostró David Goodman en sus investigaciones sobre la actividad marítima y estado de las fuerzas navales españolas en el siglo XVII (1997, 2001), en su momento se diseñaron proyectos con la clara intención de aumentar el gasto en materia naval, pero el desastroso estado de la Real Hacienda los hizo fracasar, o bien los lastró, y no poco; este fue el caso, por ejemplo, de la ampliación de la Armada del Mar Océano. Aunque también es cierto que tras esa tradicional visión historiográfica sustentada sobre la idea de crisis y decadencia del siglo XVII hispánico a la que nos hemos referido se ocultan algunos destacados logros marítimos, como la expedición de los hermanos Nodal, la cual constituye una demostración fehaciente de la capacidad que poseía la España del momento en el campo científico y naval. Así, y en un contexto que ha sido entendido tradicionalmente como de decadencia de la ciencia española, surge la oportunidad de poner a prueba la potencia real que tenía la maquinaria científica y técnica que se había venido diseñando desde los tiempos de Felipe II. Y es que desde mediados del siglo XVI, la monarquía había potenciado la figura del cosmógrafo y la del piloto mayor a través de las iniciativas y propuestas presentadas en el Consejo de Indias. Al respecto, la creación de la Academia de Matemáticas por Felipe II redundó, por ejemplo, en el perfeccionamiento de los procedimientos e instrumentos náuticos y contribuyó a la formación de brillantes cosmógrafos, como el mencionado Diego Ramírez de Arellano, quien aplicaría con eficacia su conocimiento a los problemas de navegación que le fueron surgiendo (Díaz Hernández, 2012, p. 10, pp. 15-17 y p. 37).

Por otra parte, la expedición de los hermanos Nodal ofreció la oportunidad de testar y poner en práctica las medidas de Felipe III en el campo naval y, en particular, aquellas referidas a la reglamentación en la construcción de los navíos. El estudio de Carla Ranh Phillips (1986), centrado en las primeras décadas del siglo XVII, analiza esas medidas a través del estudio de las ordenanzas puestas en vigor con la intención de regular la construcción naval (1607, 1613 y 1618); unas medidas que tenían por objeto controlar más de cerca esta industria, regular el tamaño y configuración de los barcos o establecer donde se debían obtener los materiales y donde reclutar la mano de obra. En este sentido, las innovaciones más importantes consistieron en reducir a fórmulas fijas el tamaño y las proporciones de los navíos, abandonando así el sistema tradicional de que cada barco fuese una creación única (Ranh Phillips, 1986, pp. 54-55; Valdez-Bubnov, 2011, pp. 74-85). Precisamente en 1618, la última ordenanza, culmina la legislación naval del reinado de Felipe III, la cual se traduce para la empresa expedicionaria de los Nodal en la construcción de dos embarcaciones conforme 
a la mejor tecnología naval ibérica del momento. Así se botaron la capitana, Nuestra Señora de Atocha, al mando de Bartolomé, y la almiranta, Nuestra Señora del Buen Suceso, al de su hermano, Gonzalo. El tonelaje de ambas naves y su diseño son un claro reflejo de esas medidas, como también lo son otros aspectos de la expedición en los que participaron reputados marinos como Diego Brochero o Tomé Cano, autor del Arte para fabricar, fortificar y aparejar naos de guerra y mercantes $(1621)^{18}$.

Asimismo, se decidió que la construcción de los barcos y la obtención de los materiales y la marinería para la expedición habrían de realizarse en Portugal. Conforme a ello, las carabelas, de 80 toneladas cada una, fueron construidas en los astilleros de Lisboa siguiendo las ordenanzas de 1618, y se las dotó de pertrechos y provisiones para diez meses. En paralelo, se ordenó al mayordomo de la artillería de la ciudad de Lisboa, Alonso Pérez de Santa Cruz, que entregase 20 quintales de pólvora, 7 quintales de cuerda, 36 arcabuces, 24 mosquetes, 24 picas y 24 chuzos a don Fernando Alvia de Castro, proveedor de la Armada en el Reino de Portugal, y que todo ello fuese embarcado en los dos navíos ${ }^{19}$.

Aunque la expedición tenía una misión científica, la travesía no estaba exenta de peligros. De hecho, a su regreso a la península tuvieron que enfrentarse a tres barcos corsarios a la altura de las islas Azore ${ }^{20}$. Por lo demás, para la expedición se reclutaron de manera forzosa un total de 80 marineros portugueses (40 para cada nave), a los que se les adelantó la paga de diez $\operatorname{meses}^{21}$. Una medida que buscaba aquietar el temor de la marinería ante los imponderables de enfrentarse a una tierra ignota y a las conocidas calamidades sufridas por otros navegantes que tomaron la derrota del estrecho de Magallanes. Al respecto, vale la pena recordar la inteligencia de los Nodal

AGI, Patronato, legajo 33, N. 5, R. 4, Tomé Cano, Antonio Moreno, Alonso Bernal, Simón Saneado y Francisco de Tejada sobre la conveniencia de armar dos o tres barcos para la expedición de los hermanos Nodal y propuesta del derrotero que llevaría la expedición. Acompaña la relación del doctor Juan Arias de Loyola, sobre el derrotero que debían llevar, designando el camino, los bajos, alturas y grados, etc., Sevilla, julio de 1618; AGI, Patronato, 33, N.4, R.5., Relación de las provisiones necesarias para embarcar en cada una de las carabelas de la expedición de los hermanos Nodal al estrecho de Magallanes que van al mando de Bartolomé García de Nodal, Lisboa, 12 de mayo de 1618; AGI, Patronato, 33, N. 5, R. 5, Cálculo del coste económico de la construcción y aparejo de una de las carabelas realizado por Diego Brochero, Madrid, 12 de julio de 1618.

19 ANTT, Corpo Cronológico, Parte II, maço 335, doc. 182., Orden de Felipe III trasladada por el Marqués de la Hinojosa para que el mayordomo de artillería, Alonso Pérez Santa Cruz, entregue a D. Fernando Alvia de Castro, proveedor de la armada en el Reino de Portugal, munición y armas para embarcar en las dos carabelas de la expedición de los hermanos Nodal, Madrid, 10 de agosto de 1618; ANTT, Corpo Cronológico, Parte II, maço 335, doc. 182 f. 2 v.-3 r., D. Fernando Alvia de Castro, proveedor de la armada en el Reino de Portugal, declara la munición y armas para embarcar en las dos carabelas para la expedición de los hermanos Nodal que recibió de Alonso Pérez de Santa Cruz, mayordomo de la artillería en la ciudad de Lisboa, Lisboa, 17 de septiembre de 1618.

$20 \quad$ Nodal, 1621, Relación diaria... h. 63 v. y 64 r.

$21 \quad$ Nodal, 1621, Dedicatoria al lector, h. $1 \mathrm{v}$. 
en no alargar la travesía más allá de lo estrictamente necesario. El regreso de todos los tripulantes de la expedición con vida y la ausencia de incidentes importantes a bordo fue algo realmente extraordinario para la época.

Por lo demás, todo ello puede considerarse fruto de la posible y necesaria cooperación entre españoles y portugueses que se dio durante la Unión Ibérica, la cual alcanzaría el ámbito ultramarino cuando la expedición arribó el 15 de noviembre de 1618 a Río de Janeiro. La escala en este puerto de la América portuguesa fue crucial para el éxito de la expedición. Además del necesario aprovisionamiento y aguada, allí pudieron reparar las carabelas y hacer la modificación de sus puentes antes de continuar el viaje ${ }^{22}$.

Otro punto a considerar es el ámbito concreto en el que se desarrollaron las exploraciones marítimas. Con anterioridad a la de los Nodal, el rey Felipe III y su Consejo de Estado - aún con la oposición del Consejo de Indias - patrocinaron el primer viaje del portugués Pedro Fernández de Quirós en busca de la Terra Australis (1605-1606). Una empresa que nacía en un contexto favorable, pues contaba con el antecedente de los viajes exploratorios de Álvaro de Mendaña en el Pacífico y el interés de la cartografía de la época por encontrar la Quarta Pars Incognita, cuyo descubrimiento se pensaba apuntalaría la primacía ibérica en aquel espacio ultramarino, amenazado desde finales del siglo XVI por la penetración holandesa. Por su parte, la oposición del Consejo de Indias a los proyectos de Quirós puede explicarse por el temor a que el posible descubrimiento de la citada Terra Australis pudiese acabar perjudicando o poniendo en peligro el monopolio mercantil de Sevilla. Además, la elección de un portugués para encabezar el negocio despertaba no pocos recelos, al interpretar sus proyectos como una posible injerencia portuguesa en las áreas de expansión castellana. Sin embargo, el viaje de Quirós no pasó de ser una accidentada travesía hasta las Nuevas Hébridas y distó de obtener los resultados esperados. A la vista de su fracaso, la corona prohibió en el futuro nuevos viajes exploratorios por el Pacífico, argumentando la imposibilidad de colonizar y defender más tierras. Aun así, Quirós escribiría durante siete años sus famosos memoriales, consiguiendo finalmente que el monarca patrocinase un nuevo viaje que no llegó a concluirse en 1615 (Fernández de Quirós, 2002, pp. 10-29; Valladares, 2001, pp. 17-20).

Mientras tanto, los holandeses ya habían organizado en 1598 las primeras expediciones al estrecho de Magallanes con el objetivo de llegar a los mercados asiá$\operatorname{ticos}^{23}$. A comienzos del siglo XVII, la solvencia financiera de sus comerciantes y

Nodal, 1621, Relación diaria... h. 5 v.

La primera fue la de Jacques Mahu y Simon de Cordes (1598-1600) y tres meses después la expedición de Oliver van Noort (1598-1601). 
la capacidad de organización de sus compañías mercantiles fueron los motores de estas expediciones. Por el contrario, en el ámbito hispánico la iniciativa mercantil privada no pudo desarrollarse en este sentido debido a las restricciones monopolísticas estatales. De hecho, la actividad marítima expedicionaria estaba subordinada a la voluntad y a los objetivos del monarca, o de sus delegados en Indias, los virreyes. Conforme a ello, en España no se podía emprender una expedición como la de 1618 si ésta no justificaba la defensa de los intereses de la monarquía y, dicho sea de paso, siempre bajo circunstancias apremiantes y no por diligencia previsora, tal y como ocurriría al conocerse el descubrimiento de Le Maire.

En estas circunstancias, se comprende que fuese en la joven república holandesa dónde e diesen las condiciones que permitirían llevar a cabo el descubrimiento del nuevo paso austral. Tras fundarse la VOC, en 1602, ésta intentó impedir la navegación de buques holandeses ajenos a la compañía por las tradicionales rutas de acceso a los mercados asiáticos. Las dos vías que cabía seguir para ello eran o bien navegar hacia oriente doblando el Cabo de Buena Esperanza o bien hacerlo hacía occidente atravesando el estrecho de Magallanes.

Estas dificultades de la VOC hicieron que los comerciantes holandeses excluidos de estas rutas - y que no querían verse privados de aquel comercio-, se determinasen a buscar un nuevo paso entre el Atlántico y el Pacífico. Para ello, Isaac Le Maire, uno de los mayores accionistas de la VOC, fundó la Compañía Austral (Australische of Zuid Compagnie) con sede en Hoorn y fueron su hijo Jacob y el experto navegante Willem Corneliszoon Schouten quienes se aventuraron a abrir una nueva vía comercial que los conectase con el Pacífico, evitando de este modo el paso por el estrecho de Magallanes (Carrasco González, Gullón Abao y Morgado García, 2016 pp. 67-68). Pese a que a comienzos del siglo XVII la mayoría de los navegantes probablemente seguía pensando que la costa sur del estrecho de Magallanes pertenecía a la Terra Australis, la insularidad de la Tierra de Fuego ya había sido insinuada tiempo atrás. Sir Francis Drake, en su viaje de 1578, tras cruzar el estrecho de Magallanes alcanzó los 57 grados y 20 minutos de latitud sur, situándose de este modo en la longitud del cabo de Hornos. Aunque su diario de viaje no da noticia de este descubrimiento, sí sugiere la existencia de una posible ruta al sur, dando por cierta así la mencionada insularidad de Tierra de Fuego. Por su parte, Pedro Fernández de Quirós también se hacía eco en 1605-1606 del testimonio de un geógrafo que estaba al servicio del corsario Richard Hawkins, quien afirmaba la posibilidad de que hubiese un paso más al sur, cuestión esta que Quiros planteará luego en sus memoriales:

«... Es de advertir que se suele decir que el estrecho de Magallanes no es solo, y también se dice que la tierra de la otra banda del es una isla y que por fuera della 
hay mar abierto por donde se puede pasar del a otra mar. Yo digo que puede ser que sea así lo que se dice; más que lo creeré cuando sea visto por vasallos de V.M. enviados al efecto». (Fernández de Quirós, 2002, p. 324)

El seguimiento de esta intuición fue lo que en su día llevó a la expedición de Le Maire y Schouten a navegar hasta los 57 grados latitud sur y encontrar así un nuevo paso interoceánico situado más al sur del de Magallanes.

\section{Restauración simbólica del poder}

Cuando la expedición holandesa descubrió el nuevo paso, lo bautizaron con el nombre de Le Maire. Esta nueva ruta se disponía entre la tierra que llamaron Mauritius van Naßau, en honor de Mauricio de Nassau (1584-1625), futuro Príncipe de Orange, y las islas nombradas Staten Landt, en recuerdo de los Estados de la República. El 31 de enero de 1616 la expedición alcanzó los 57 grados y 48 minutos de la latitud sur a la altura de un cabo que bautizaron también como Caep Hoorn, esta vez en honor de la ciudad holandesa del mismo nombre.

Este periplo marítimo, que los llevaría hasta las islas Molucas, se truncó en Java, cuando el gobernador de la VOC, Jan Pieterszoon Coen, los apresó, procediendo a desacreditar el descubrimiento del nuevo paso al acusarlos de haber navegado por el estrecho de Magallanes, reservado por la VOC para sus propios barcos (Carrasco González, Gullón Abao y Morgado García, 2016, p. 69). Sin embargo, esto no impidió que la relación del viaje de Le Maire y Schouten fuese publicada y que causase un gran estupor en la época, al saberse que sólo fueron necesarios dos días, el 24 y 25 de enero de 1616, para alcanzar los Mares del Sur a través de este nuevo paso, en contraste con la larga y difícil travesía que requería la navegación por el estrecho de Magallanes, la cual imponía no pocas penitencias y dificultades a los navegantes.

La rápida reacción de la corte de Madrid al descubrimiento de esta nueva ruta interoceánica debe entenderse más allá de la argumentada amenaza que el mismo suponía para la seguridad del Pacífico, pues implicaba la existencia de otra amenaza no menos grave: que unos súbditos rebeldes poseyesen un conocimiento superior al atesorado hasta entonces por la Casa de Contratación, visto que el saber científico acumulado sistemáticamente desde comienzos de la edad moderna sobre el Nuevo Mundo estaba en estrecha relación con el poder y el dominio colonial español (Brendecke, 2012). De este modo, el objetivo de la expedición de los Nodal en 1618 no era materializar un proyecto de fortificación —intentado sin éxito en las décadas pasadas, como luego veremos - sino desarrollar una misión relacionada con la mencionada acumulación de conocimiento. La Cédula Real donde se detallan las instrucciones de 
la expedición es clara al respecto: se les ordena explorar la costa desde Brasil hasta el cabo de las Vírgenes, el reconocimiento cartográfico preciso del estrecho de Magallanes y la Tierra de Fuego, el dibujo de los aspectos del terreno y la realización de mediciones y cálculos que sirvan para mejorar la navegación. Una vez encontrado y pasado el estrecho de Maire, se ordena a la expedición «reconocer la punta y cabo que está en 56 grados y medio conforme a la figura de la planta que lleváis» ${ }^{24}$.

Dicho esto, es interesante que nos refiramos al artículo publicado en 1940 por Julio Guillén, quien sacaba a la luz tres cartas de navegación del estrecho de Le Maire, que relacionaría con la contratación y traslado a España en 1618 de los pilotos flamencos Pedro de Letre, Joan Witte y Valentin Tansen. Este marino investigador comprobó que esas cartas náuticas, elaboradas a comienzos de 1618, son muy similares a la aparecida en la relación del viaje publicada por Le Maire y Schouten. De hecho, la toponimia analizada por Guillén en la carta náutica de Pedro de Letre, conservada en la Real Academia de la Historia, invita a pensar que podría ser una copia de la de Le Maire ${ }^{25}$. De ser así, se advertiría entonces la existencia de una relación entre este material y los preparativos de la expedición de los hermanos Nodal, y se evidenciaría asimismo la existencia de una verdadera «guerra de inteligencia» al respecto, la cual, en estas fechas, pasaba por el control y resguardo de la información sobre la navegación; una información que era de sumo interés para el Consejo de Indias, muy preocupado por el descubrimiento de este nuevo paso interoceánico (Guillén, 1940, pp. 35-62).

Lo cierto es que los términos de la contratación de los citados pilotos holandeses son conocidos gracias a la conservación de la correspondencia que mantuvieron Francisco de Tejada y Mendoza — presidente de la Casa de Contratación-y el Consejo de Indias ${ }^{26}$. Por ella sabemos que el archiduque Alberto y el conde de Egmont se encargaron en Flandes de acordar las condiciones del contrato con los mencionados pilotos, quienes viajaron luego a España con la relación del asiento que se les había hecho. El primero en llegar a Sevilla fue Pedro de Letre, que había embarcado en la expedición de Spilberg en 1617. Luego, en marzo, llegaría Joan Witte y unos días más tarde, Valentin Tansen ${ }^{27}$. Una vez admitidos y dados por hábiles se les pagaron «ciento y cincuenta florines de a veinte plaças, moneda de Brabante, cada mes sirviendo o no sirviendo después de admitidos». Además, dispusieron de 200 florines

\footnotetext{
$24 \quad$ AGI, Patronato, 33, N.4, R.5 (3), fechada en San Lorenzo de El Escorial el 26 de agosto de 1618.

25 RAH, Colección Departamento de Cartografía y Artes Gráficas, C-003-086.

26 AGI, Patronato, 33 N. 5 R. 7, Cartas de don Francisco de Tejada y Mendoza sobre el apresto de pilotos y carabelas que debían ir al reconocimiento del estrecho de Magallanes. Son cuatro cartas fechadas en Sevilla, 20 de marzo y 10, 17, y 28 de julio de 1618. 
cada uno para comprar «algunas cosas curiosas tocantes a el dicho oficio y arte», y una vez presentados donde les fuere ordenado se les dieron otros 200 florines más ${ }^{28}$. Y todo ello, a pesar del maltrecho estado de la Hacienda Real, si bien, como reconoce el presidente de la Casa de Contratación, estos pilotos eran gente que «tanto conviene tener contenta con la paga y buen tratamiento» ${ }^{29}$. Con ellos se reunió más adelante, en presencia del cosmógrafo mayor de la Casa de Contratación, al objeto de debatir sobre la navegación por el estrecho de Magallanes ${ }^{30}$. Gracias a otra misiva, dirigida esta vez al secretario Pedro de Ledesma y fechada el 10 de julio de 1618, sabemos que el trabajo cartográfico de los holandeses había permitido elaborar al cosmógrafo mayor de la Casa, Antonio Moreno, una carta náutica del nuevo paso, la cual fue remitida a la Junta de expertos ${ }^{31}$. Esta carta náutica serviría de guía a la expedición de 1618, siendo «la figura de la planta» que se menciona en las instrucciones de la Cédula Real anteriormente citadas ${ }^{32}$.

Aunque la correspondencia de Tejada sólo nos permite seguir el rastro de los pilotos hasta su traslado a la Junta, todo indica que debieron embarcar con los Nodal. El cosmógrafo de la expedición relata en su diario como al regreso de la expedición se contrastó la información de las dos cartas náuticas resultantes del viaje para confeccionar el mapa que finalmente se publicó. Una de las cartas presentadas era suya y otra de los Nodal, la cual sospechaba había sido realizada por uno de los pilotos flamencos durante el viaje, pues así «se dixo entre los marineros, que un piloto flamenco que iba en las carabelas la hizo y se la dio» ${ }^{33}$. También en la relación del viaje se hace patente la presencia de dichos pilotos, cuando se lee en ella que estando en Río de Janeiro reparando las carabelas «entraron los pilotos Flamencos y Portugueses a dezir que por ningún caso se podía salir del puerto sin hazer los puentes a las carabelas ${ }^{34}$. En todo caso, la participación de estos hombres en la expedición fue clave para el triunfo de la empresa marítima capitaneada por los Nodal, ya que, en aquel momento, las informaciones más precisas sobre el estrecho de Magallanes y su navegación estaban contenidas en el libro de Pedro Sarmiento de Gamboa que, según Francisco de Tejada, se guardaba en el archivo del Consejo ${ }^{35}$. A nadie se le escapa que a nivel interno este valioso conocimiento estaba relacionado

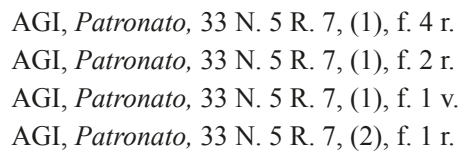
en el Archivo Histórico Nacional (en adelante AHN), Colección documentos de Indias, Car.1, N.4. BNE, ms. 3190, f. 181.

Nodal, 1621, Relación diaria... h. 5 v.

AGI Patronato, 33 N. 5 R. 7, (3), f. 1 v. 
con el poder y el dominio del Nuevo Mundo, que se recopilaba para elaborar una cartografía lo más precisa posible y realizar las cartas náuticas, las cuales eran una de las armas más apreciadas en la época por cualquier potencia extranjera, de ahí que su información estuviese sometida a un riguroso secreto y control por parte de las autoridades (Portuondo, 2009). Sea como fuere, a este nivel los engranajes de la política exterior hispana estaban perfectamente engrasados y a pleno rendimiento. Prueba de ello es que a comienzos de 1618, cuando se publica la relación del viaje de Le Maire, ya se encontraban trabajando en España los mencionados pilotos holandeses para el Consejo de Indias.

Por otra parte, la expedición organizada en 1618 es la respuesta dada a la profanación de un espacio geográfico considerado como propio, sobre el que debía restituirse el legítimo poder de la monarquía hispana. La corona basaba su titularidad sobre las tierras australes en las concesiones contenidas en las bulas papales que se le habían otorgado en su día. Frente a ellas, las potencias extranjeras, como Holanda o Inglaterra, apelaban al principio del Derecho romano de la res nullius, por el cual las tierras no ocupadas eran un bien de la humanidad hasta que se hiciera uso de ellas. En consecuencia, el primero en hacerlo se convertía de inmediato en su propietario (Elliott, 2011, p. 65). Efectivamente, en aquellas latitudes alejadas del centro del imperio filipino no había ni población ni asentamientos ibéricos. Tras el intento infructuoso a finales del siglo XVI de poner en pie las fundaciones de en «Nombre de Dios» y «Ciudad del Rey Felipe» en el estrecho de Magallanes por Sarmiento de Gamboa, la corona no volvería empeñar más recursos materiales y humanos en esa dirección. Además, el Consejo de Indias adoptaría una actitud reticente al patrocinio exploratorio de aquellas latitudes al no temerse la ocupación de unas tierras lejanas, frías y yermas.

No habiendo ocupación física del terreno, cabría preguntarse a qué tipo de conservación y reputación nos estamos refiriendo cuando hablamos de la expedición de los hermanos Nodal. En este punto, convendría aclarar que lo hacemos a aquello que John Elliott definió en su día como la «ocupación simbólica del espacio» (2011, p. 64), la cual se manifestaba mediante una serie de rituales que, en este caso, se concretaban en la imposición de nombres a los lugares descubiertos. Estas nuevas designaciones introducían las tierras recién descubiertas en el mundo ideológico de sus descubridores. Por esta razón, la cartografía formaba parte también de la toma de posesión simbólica del espacio, pues dejaba constancia de ello en los mapas a la vez que reafirmaba los derechos que uno tenía sobre el territorio cartografiado frente a potenciales rivales que quisiesen discutir su propiedad (Elliott, 2011, pp. 64-71, pp. 68-69). Sirvan de ejemplo los nombres con los que Le Maire y Schouten fueron bautizando sus descubrimientos geográficos en aquella parte del mundo. El contra- 
punto a este proceder nos lo ofrece la expedición de los Nodal, cuyos componentes se cuidaron de renombrar todos aquellos lugares al, por ejemplo, llamar al estrecho de Le Maire, estrecho de San Vicente, y al cabo de Hoorn, cabo de San Ildefonso (Mapa 2). De hecho, en la relación publicada del viaje se expresa claramente la idea que se quiere proyectar: se hizo el «descubrimiento» del «nuevo» estrecho de San Vicente, el cual «descubren» y toman posesión de forma simbólica: «echamos nuestras banderas, disparamos pieças, dando muchas gracias a Dios por la merced tan grande que nos hizo» ${ }^{36}$.

La expedición de los Nodal regresó a Sanlúcar de Barrameda el 9 de julio de 1619. Constituyó un éxito para la Monarquía Hispánica y aportó una valiosísima información al Consejo de Indias. Tanto es así que sus resultados cartográficos no serían superados hasta la llegada a la zona de las expediciones científicas españolas de finales del siglo XVIII. La relación del viaje se publicó en Madrid en 1621, apareciendo en su primera página un frontispicio barroco adornado con los grabados de Jean de Courbes (1592-1641). El magnífico mapa de las tierras australes que se adjuntó a la relación es también un testimonio visual de la empresa ibérica ${ }^{37}$. Es el primer trabajo conocido del portugués Pedro Teixeira Albernas (c. 1595-1662) — hijo a su vez del cosmógrafo mayor del Reino de Portugal-, quien llegaría a ser cartógrafo real y autor tanto del conocido Atlas del Rey planeta (1634) como del famoso plano de la villa de Madrid (1656), ya en el reinado de Felipe IV ${ }^{38}$. La obra se cierra con referencias a los laureados servicios de los capitanes y era el escaparate, la muestra más clara y evidente, del triunfo del poder naval buscado por la corte de Madrid. Metafóricamente hablando, era un gran lienzo en el que se plasmó el triunfo de un imperio que quería salvaguarda su honor y prestigio.

\section{Consideraciones finales}

El resultado propagandístico de la expedición de los Nodal fue muy limitado. Las relaciones de viajes de las potencias marítimas rivales gozaron de más difusión en la época gracias a su mayor potencia editorial. Un claro ejemplo de ello es lo sucedido con la de Le Maire y Schouten, publicada en Ámsterdam en 1618. En 1619 sería traducida al latín, al español, al francés y al inglés, siendo la relación de viaje

Nodal, 1621, Relación diaria...h. 30 v. - 31 r.

Mapa plegado entre h. 34 y 35. Dimensiones: 395 x 344 mm. Destaca el ejemplar que se conserva en la BNE procedente de la Biblioteca Real que contiene dicho mapa iluminado: BNE, R/4017.

38 RAH, 2013, vol. XLVII, pp. 903-905. 


\section{Mapa 2. La expedición de los hermanos Nodal en el estrecho de Magallanes y Tierra de Fuego}

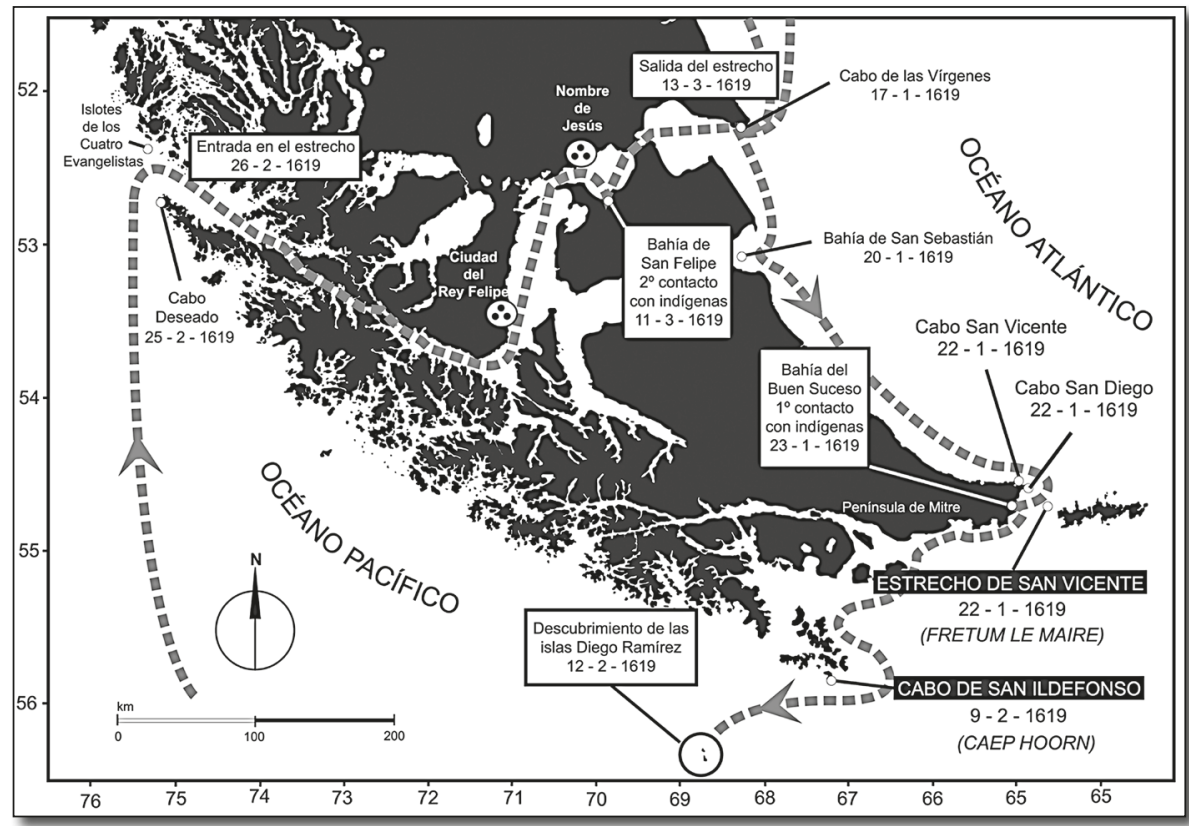

Fuente: Elaboración propia a partir de la relación del viaje.

más editada durante todo el siglo XVII (Duviols, 1985, p. 391) ${ }^{39}$. Otra prueba más de esta escasa difusión, la tenemos en la notoriedad alcanzada por la compilación de los viajes europeos a América realizada por Theodor de Bry, la cual es contemporánea de la expedición de los hermanos Nodal. En la obra de Bry - que fue la visión que de América tuvieron los europeos de los siglos XVII y XVIII - aparece la expedición holandesa de 1616 y un grabado que sitúa a Schouten a la altura de Magallanes por el descubrimiento del nuevo estrecho. La de los hermanos Nodal no aparece, y ello, a pesar de ser un hito en la navegación y del importante reconocimiento cartográfico que hicieron de la zona. Es más, tras la expedición de Le Maire y Schouten, sería la

39 En 1619 se realizan dos traducciones al latín en Ámsterdam: la de Guilielmun Ianfonium y Petrum Kaerium. Ese mismo año también se publica en español (Bernardino de Guzmán, Madrid), en francés (Jan Jansson, Ámsterdam) e inglés (Nathanaell Newberry, Londres). Durante el siglo XVII la obra se volvió a editar en Holanda en los siguientes años: 1618, 1619, 1624, 1632, 1637, 1644, 1648, 1649, 1651, 1655, 1661, 1663, 1664 y 1690. 
del holandés Jacobo L'Hermite la siguiente en ser recopilada por Bry en 1623 (Bry, 1992, p. 9, pp. 346 y ss.).

Como puede verse, es cierto que hubo una visión de la historia que se publicitó mejor e influyó más en el devenir historiográfico europeo de las siguientes décadas. Pero, a nuestro juicio, sería injusto imputar exclusivamente a ello el olvido de la española. La política de seguridad y atesoramiento de conocimientos llevada a cabo con respecto a las cartas náuticas y a las demás informaciones cartográficas, determinó en la época la ocultación de un manuscrito que, paradójicamente, contenía la ciencia náutica más refinada, actualizada y elaborada de la España de principios del siglo XVII. Por tal motivo el manuscrito que nos ocupa no llegó a publicarse en su momento, de hecho, no vería la luz hasta el siglo XIX ${ }^{40}$. Así pues, tal y como recientemente ha señalado Juan Pimentel, la invisibilidad, el carácter inaparente, fue uno de los rasgos de la ciencia española, explicable por quedar muchos trabajos, documentos y conocimiento acumulado, oculto durante mucho tiempo o en manos de otras naciones. Son estos los capitales sumergidos de la ciencia española, que fueron invisibles para la historiografía europea (Pimentel, 2016, pp. 439-444), al igual que lo fue el manuscrito de Ramírez de Arellano y, a la postre, el logro de la expedición de los hermanos Nodal.

Aquel logro supuso el culmen de una etapa del conocimiento cartográfico de la zona magallánica y la Tierra de Fuego, que se había iniciado aproximadamente cien años antes con el descubrimiento del estrecho de Magallanes. Un logro que volvió a situar a la Monarquía Hispánica en la primera fila del campo de las expediciones geográficas, solo que esta posición pronto se perdería ante las potencias rivales. La corona, inmersa en la espiral belicista iniciada con la Guerra de los Treinta Años (1618-1648), se durmió en los laureles de la exitosa empresa naval de Felipe III sin volver a atender la exploración de la región magallánica hasta finales de siglo XVII, cuando ya la ventaja de las potencias marítimas rivales era notoria.

Hubo además otros factores que tampoco ayudaron a avanzar en la actividad exploratoria española: la rígida regulación mercantil del sistema monopolista, que establecía unas rutas marítimas y terrestres bien definidas y controladas por el poder, y la hostilidad de las oligarquías comerciales (criollas y peninsulares) nacidas al calor de ese monopolio, las cuales eran abiertamente hostiles a la apertura de nuevas rutas marítimas. Tampoco la corona se vio necesitada de ello, pues su mayor preocupación económica era la plata americana, que seguía llegando a la metrópoli a través de un

$40 \quad$ Martín Fernández de Navarrete lo mencionará en la Biblioteca marítima española (1845, p. 355). Hasta 1866 no se publicará su transcripción en el Anuario de la Dirección de Hidrografía (pp. 206-291). 
sistema de flotas que discurría sobre unas derrotas sólidamente establecidas. Por el contrario, el funcionamiento del sistema mercantil holandés auspició el nacimiento de la Compañía Austral y alentó a Le Maire a que emprendiese la búsqueda de un nuevo paso interoceánico. La Tregua de los Doce Años favoreció una intensa actividad marítima holandesa en las Indias, a la vez que la nueva potencia cimentaba su poderío naval sobre un armazón teórico que hizo tambalear el imperio ultramarino ibérico y la ideología que lo sustentaba. Así fue percibido en aquel momento en la península, de tal modo que se intentó dar respuesta a esta ofensiva tanto en el campo teórico como en el práctico. Conforme a ello, cuando se produce el descubrimiento del nuevo paso interoceánico por los holandeses, España responde con la organización de la expedición de los hermanos Nodal, la cual constituye un ejemplo de recuperación simbólica del poder a partir del empleo de aquella poderosa arma que era la cartografía.

En suma, el éxito de esa expedición no se debió al azar, sino a la oportunidad que tuvo la Monarquía Hispánica durante el reinado de Felipe III de poner en juego la capacidad de sus hombres de ciencia y de sus experimentados capitanes, además de ser capaz de hacer reales las medidas de revitalización naval que se habían pensado para ello. Asimismo, también se debe a una cooperación ibérica durante la unión dinástica de España y Portugal. En el contexto político que hemos analizado, sintetizable en la frase que se entrecomilla en el título de este artículo, la expedición de los hermanos Nodal fue una demostración del potencial ibérico de la época. Un éxito que no tuvo eco en la historiografía, al vivir sumergido en las «decadentes tinieblas» del siglo XVII. 


\section{Bibliografía}

Allen, Paul C. (2001), Felipe III y la Pax Hispánica. 1598-1621, Madrid, Alianza Editorial.

BRENDECKE, Ardnt (2012), Imperio e información. Funciones del saber en el dominio colonial español, Madrid-Frankfort, Iberoamericana Vervuert.

BRY, Theodor (1992), América de Bry, 1590-1634, Gereon Sievernich (ed.), Madrid, Siruela.

Carrasco González, Guadalupe, Gullón Abao, Alberto y Morgado García, Arturo (2016), Las expediciones cientificas en los siglos XVII y XVIII, Madrid, Editorial Síntesis.

Céspedes del Castillo, Gonzalo (1983), “América Hispánica (1492 - 1898)” en Tuñón de Lara, Manuel (dir.), Historia de España, tomo VI, Barcelona, Editorial Labor.

Cotarelo Valledor, Armando (1935), “El P. José de Zaragoza y la Astronomía de su tiempo", en Estudios sobre la Ciencia española del siglo XVII, Asociación Nacional de Historiadores de la Ciencia Española, Madrid, Gráfica Universal, pp. 70-233.

Depósito Hidrográfico de la MArina (1866), "Discurso y derrotero del viaje que se hizo a los estrechos de Magallanes y de San Vicente, por Diego Ramírez de Arellano", en Anuario de la Dirección de Hidrografía, Año IV, Madrid, Depósito Hidrográfico, imprenta de T. Fortanet, pp. 206-291.

DíAz HERnÁNDEZ, Ignacio (2010), Estudio preliminar y transcripción del manuscrito de Diego Ramírez de Arellano "reconocimiento de los estrechos de Magallanes y San Vicente, con algunas cosas curiosas de navegación”(1621). Tesis doctoral inédita, Valencia, Universitat de València.

Duviols, Jean-Paul (1985), L'Amérique espagnole vue et rêvée. Les libres de voyages de Christophe Colomb à Bougainville, París, Editions Promodis.

ElliotT, John H. (2009), España, Europa y el mundo de ultramar (1500 - 1800), Madrid, Taurus.

Elliott, John H. (2011), Imperios del mundo atlántico. España y Gran Bretaña en América, 1492-1830, Madrid, Taurus.

Elliott, John H. y De la PeÑA, José F. (1978), Memoriales y cartas del Conde Duque de Olivares, Madrid, Alfaguara.

FÉrnandez de Navarrete, Martín (1842-1852), Biblioteca Marítima, vol. I, Madrid, Imprenta e la Vda de Jordán e hijos.

Fernández de Quirós, Pedro (2002), Memoriales de las Indias Australes, Pinochet de la Barra, Óscar (ed.), Madrid, Colección Crónicas de América, Dastin. 
FERnÁndez Duro, Cesáreo (1972), Historia de la Armada Española desde la unión de los reinos de Castilla y Aragón, vol. III, Madrid, Museo Naval (reedición de la obra original de 1895-1903).

FERnÁndeZ Villamil, Enrique (1952), "Una noticia sobre la familia y bienes de Gonzalo de Nodal y Bartolomé García de Nodal”, diario El Faro de Vigo, 28 -XI.

Ferrer de Couto, José (1849), Historia de la Marina Real Española, desde el descubrimiento de las Américas hasta el combate de Trafalgar, vol. 2, Madrid, Ducazcal.

Filgueira Valverde, José (1944a), Salas Navales, Pontevedra, El Museo de Pontevedra.

Filgueira Valverde, José (1944b), Sobre la Historia Marítima de Galicia, Madrid, Real Sociedad Geográfica.

Filgueira Valverde, José (1946), Archivo de Mareantes, Pontevedra, Museo de Pontevedra e Instituto Social de la Marina.

Filgueira Valverde, José (1963), Pontevedra y el mar. Textos para la antología de una tradición, Pontevedra, Imprenta Hogar Provincial.

Filgueira Valverde, José (1965), Noticias de Indias en la Relación del viaje de los capitanes Bartolomé y Gonzalo de Nodal, Pontevedra, Imprenta Hogar Provincial.

Filgueira Valverde, José (1979), Los Nodales: Capitanes de mar y descubridores, en el IV centenario del nacimiento de Gonzalo Nodal, Pontevedra, Diputación Provincial de Pontevedra.

Fulgosio, Fernando (1867), Crónica de la Provincia de Pontevedra, Madrid, Editores Rubio y Compañía.

GÁndara, Felipe de la (1987), Armas y triunfos. Hechos heroicos de los hijos de Galicia, Vigo, Nova Galicia (Reproducción facsímil de la edición de 1662, Madrid).

Gómez CANEDO, Lino (1991), Los gallegos en los descubrimientos y las exploraciones, A Coruña, Xunta de Galicia.

González García - PAZ, Sebastián (1961), "El conde de Gondomar y los Nodales", El Museo de Pontevedra, Separata, tomo XV, pp. 5-11.

GonzÁlez Zuñiga, Claudio (1846), Historia de Pontevedra, Pontevedra, Imprenta Viuda de Pintos.

Goodman, David (1997), Spanish Naval Power, 1589-1665: Reconstruction and Defeat, Cambridge, Cambridge University Press.

Goodman, David (2001), El poderío naval español. Historia de la armada española en el siglo XVII, Barcelona, Ediciones Península. 
Grocio, Hugo (1979), De la libertad de los mares, Madrid, Centro de Estudios Constitucionales (reedición obra original de 1609).

Guillén, Julio (1940), “Una carta inédita del estrecho de Le Maire, e identificación de otras dos anónimas del siglo XVII", Revista de Indias, 1, pp. 35-62.

Landín Carrasco, Amancio (1991), Galicia e os descubrimentos oceánicos, A Coruña, Xunta de Galicia.

López PiÑERo, José María (1979), Ciencia y técnica en la sociedad española de los siglos XVI y XVII, Barcelona, Editorial Labor.

Martínez Shaw, Carlos y Martínez Torres, José Antonio (dirs.) (2014), España y Portugal en el mundo (1581-1668), Madrid, Ediciones Polifemo.

Martínez Torres, José Antonio (2017), “Gobernar el Mundo. La polémica Mare Liberum versus Mare Clausum en las Indias Orientales (1603-1625)", Anuario de Estudios Americanos, 74, pp. 71-96. https://doi.org/10.3989/aeamer.2017.1.03

Millán, José (1920), Notas históricas sobre Varones ilustres de Pontevedra, tomo I, Pontevedra, Imprenta de La Correspondencia Gallega.

MurTeIRA André (2014), "La Carreira da Índia y las incursiones neerlandesas en el Indico occidental, 1604-1608”, en Martínez Shaw, Carlos y Martínez Torres, José Antonio (dirs.), España y Portugal en el mundo (1581-1668), Madrid, Ediciones Polifemo, pp. 299-314.

MurTeIRA, André (2008), O corso neerlandés contra a Carreira da India no primeiro quartel do século XVII, Anais de historia de Além-Mar, IX, Lisboa, CHAM.

OyARZUn, Javier (1976), Expediciones españolas al estrecho de Magallanes y Tierra de Fuego, Madrid, Ediciones de Cultura Hispánica.

Pereira Fernández, Xosé Manuel (2000), A Pontevedra de Felipe II, A Coruña, Concello de Valga.

Pérez Bustamante, Ciriaco (1928), Españoles e ingleses en América durante el siglo XVII. El conde de Gondomar y su intervención en el proceso, prisión y muerte de sir Walter Raleigh, Santiago, Editorial Paredes.

Pérez Bustamante, Ciriaco (1983), “La España de Felipe III”, en Menéndez Pidal, Ramón (dir.), Historia de España, vol. XXIV, Madrid, Espasa Calpe.

Pimentel, Juan (2016), "El peso del aire y las disciplinas invisibles. La polémica de la ciencia española como narrativa de una modernidad elusiva", en Villaverde Rico, María José y Castilla Urbano, Francisco (eds.), La sombra de la leyenda negra, Madrid, Tecnos, pp. 425-447.

Portela PÉrez, Francisco (1891), Apuntes biográficos acerca de los marinos Nodales, hijos de Pontevedra, Pontevedra, Imprenta Landín ( $2^{\text {a }}$ edición).

Portuondo, María M. (2009), Secret Science. Spanish Cosmography and the New World, Londres-Chicago, The University of Chicago Press. 
Rahn Phillips, Carla (1986), Six Galleons for the King of Spain. Imperial Defense in the Early Seventeenth Century, Baltimore, The Johns Hopkins University Press.

Real Academia de la Historia (2011), Diccionario Biográfico Español, Madrid, RAH, vol. XXII, pp. 129-130.

Real Academia de la Historia (2013), Diccionario Biográfico Español, Madrid, RAH, vol. XLVII, pp. 903-905.

Rodríguez SeoAne, Luís (1889), "El viaje de los Nodales”, Galicia Diplomática, IV, $\mathrm{n}^{\mathrm{o}} 23$, pp. 251-252.

SAmpedro y Folgar, Casto (1900), Documentos, inscripciones y monumentos para la Historia de Pontevedra, tomo I, Pontevedra, Sociedad Arqueológica de Pontevedra.

SAnZ CAMAÑES, Porfirio (2008), “Las paces con Inglaterra”, en Martínez Millán, José y Visceglia, Ma Antonietta (dirs.), Felipe III: Los Reinos, Madrid, Fundación Mapfre, vol. IV, pp. 1345-1347.

SARMIENTO, Martín (2008), De historia natural y de todo género de erudición. Obra de 660 pliegos, vol. II, Monteagudo, Henrique (ed.), A Coruña, Consello da Cultura Galega-CSIC (Reedición de la obra original de 1772).

STRADLING, Robert A. (1992), Europa y el declive de la estructura imperial española 1580-1720, Madrid, Cátedra (edición original, 1981).

Valdez-Bubnov, Iván (2011), Poder naval y modernización del Estado: política de construcción naval española (siglos XVI-XVIII), México, Iberoamericana Vervuert.

Valladares, Rafael (2001), Castilla y Portugal en Asia (1580-1680). Declive imperial y adaptación, Lovaina, Leuven University Press.

VÁZQuEZ de ACUÑA, Isidoro (1996), “La expedición de los hermanos Nodal (16181619)", Boletín de la Academia Chilena de la Historia, n 106, pp. 31-51.

VÁzQuez Lijó, José Manuel (2007), La matrícula de mar en la España del siglo XVIII. Registro, inspección y evolución de las clases de marinería y maestranza, Madrid, Ministerio de Defensa.

Vesteiro Torres, Teodosio (1874), Galería de gallegos ilustres. Marinos, tomo III, Madrid, Imprenta de Heliodoro Pérez.

Vicente Maroto, María Isabel (2001), "La expedición de los hermanos Nodal y el cosmógrafo Diego Ramírez de Arellano”, Revista de Historia Naval, 73, pp. 7-28.

VicetTo, Benito (1873), Historia de Galicia, tomo VII, Montevideo, Imprenta de la Colonia Española. 


\section{Fuentes impresas}

Nodal, Bartolomé García y Gonzalo de (1621), Relación del viaje que por orden de Su Magestad y acuerdo del Real Consejo de Indias. Hizieron los capitanes Bartolomé García de Nodal, y Gonçalo de Nodal hermanos, naturales de Ponte Vedra, al descubrimiento del Estrecho nuebo de S. Vicente y reconosimiento del de Magallanes. A Don Fernando Carrillo. Cauallero del abito de Santiago. Presidente en el mismo Consejo. Con Privilegio. Madrid, Fernando Correa de Montenegro. 